\title{
POSTPARTUM REPRODUCTIVE FUNCTION: ASSOCIATION WITH ENERGY, METABOLIC AND ENDOCRINE STATUS IN HIGH YIELDING DAIRY COWS
}

\author{
M. Reist ${ }^{a, c}$, D. Erdin ${ }^{a}$, D. von Euw ${ }^{a}$, K. Tschümperlin ${ }^{a}$, Y. Chilliard ${ }^{b}$, H. Hammon $^{c}$, \\ Y. Zbinden ${ }^{c}$, N. Künzi ${ }^{a}$, and J. W. Blum ${ }^{c}$

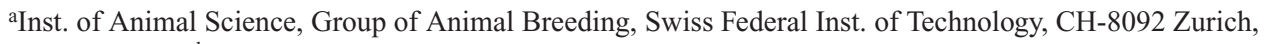 \\ Switzerland, ${ }^{b}$ Herbivore Research Unit, National Institute of Agricultural Reseach (INRA), F-63122 \\ St-Genès-Champanelle, France, and ' Div. of Animal Nutrition and Physiology, Inst. of Animal Genetics, \\ Nutrition and Housing, Univ. of Berne, CH-3012 Berne, Switzerland
}

The effect of energetic, metabolic and endocrine status upon onset of ovarian cyclicity as well as time empty and conception at first service was assessed in 90 multiparous Holstein cows (mean 9'500 kg energy-corrected milk/305 d) in a research farm in Switzerland. Dry matter intake, milk yield and body weight were measured daily from week 2 antepartum (a.p.) through wk 20 postpartum (p.p.). Milk composition was determined 4 times/wk and milk acetone was measured weekly. Blood samples for the determination of glucose, non-esterified fatty acids (NEFA), cholesterol, creatinine, albumin, urea, ß-hydroxybutyrate (BHBA), leptin, insulin, insulin-like growth factor-1 (IGF-1), growth hormone, 3,5,3'-triiodothyronine $\left(\mathrm{T}_{3}\right)$ and thyroxine $\left(\mathrm{T}_{4}\right)$ concentrations, and of activities of aspartate amino transferase (ASAT), lactate dehydrogenase (LDH) and glutamate dehydrogenase (GLDH) were taken 2 wk a.p. and in wk 1-16 and 20 p.p. between 0730-0900. Cows were gynaecologically examined weekly. The onset of first ovulation was specified by skim milk progesterone determination by a radioimmunoassay (twice/wk) and by rectal palpation. Energy balance (EB) traits were calculated and expressed as accumulated negative EB from parturition to EB equilibrium (AUC), EB nadir (EBN), rate of EB recovery following EBN (EBR), time from parturition to EBN (DEBN), and time from parturition to EB equilibrium (DEBE). Results: Resumption of ovarian cyclicity postpartum was not reflected by any of the EB traits. However, a small degree of EBN and a fast EBR were related to a short period from parturition to conception. Survival analysis with timevarying covariates revealed that high plasma concentrations of $\mathrm{T}_{3}$ and $\mathrm{T}_{4}$ p.p. were significantly associated with a high chance of an early start of the ovarian cycle, and high concentrations of glucose and cholesterol were associated with a short time empty, respectively. Conception at first service was positively associated with EB at first service and with progesterone concentration at 10-13 d after first service. However, leptin, as most other metabolic and endocrine traits, was not associated with any of the reproductive traits. In conclusion, thyroid hormones may play an important role in the onset of the ovarian cycle p.p., and a good energy status enhances the chance of conception at first service and shortens time empty. 